\title{
Simboliek in die Evangelie van Johannes
}

J G van der Watt

(UP)

\section{ABSTRACT}

\section{Symbolism in the Gospel according to John}

The use of terminology like symbol, metaphor and figurative speech is very confusing, since these terms are defined in a variety of ways. A definition of symbol is formulated, and applied to the imagery of shepherding in John 10. A few other symbols are also treated briefly to confirm the results of the symbolic analysis of shepherding in John 10.

\section{SIMBOOL OF METAFOOR?}

Die term simboliek word dikwels gebruik om figuurlike taalgebruik ${ }^{1}$ in die Evangelie van Johannes te beskryf. Ander gebruik weer die term metafoor (en nie simbool nie) as die oorkoepelende term vir figuurlike taal in die Evangelie $^{2}$. In ander gevalle word simboliek en metaforiek as sinonieme gebruik $^{3}$, of word metafore as onderafdeling van simboliek gereken. Dat dit dus ' $n$ komplekse saak is om die term simbool te definieer, veral omdat dit vir soveel verskillende betekenisse gebruik kan word, het Van Luxemburg et $a l^{4}$ reeds oortuigend betoog. Dit is natuurlik uiters verwarrend en lei tot allerhande misverstande 5 . In hierdie artikel gaan daar aan die hand van 'n spesifieke definisie van simboliek, 'n kort oorsig gegee word oor die simboliese aard van die Johannesevangelie. Daar gaan bloot eksemplaries gewerk word.

\section{Simbool? Waarvan praat ons? ${ }^{6}$}

Baldich sê tereg: "Symbol, in the simplest sense, may be used for anything that stands for or represents something else beyond it - usually an idea conventionally associated with it..."7 (klem JGvdW). 'n Simbool is gebaseer op semantiese konvensies" en is in baie gevalle "Privatsprache". Iemand sal byvoorbeeld aan 'n padteken 'n spesifieke betekenis toedig, hoewel daar in baie gevalle geen logiese verband tussen die simbool en die toegekende betekenis bestaan nie ${ }^{10}$. So 'n simbool funksioneer op die basis van konsensus, of soos Goodenough dit stel: “...we have constantly to bear in mind that the meaning or value of any given symbol is not a denotative, precise meaning, but a connotative one" ${ }^{11}$. Dit veronderstel natuurlik dat 
die leser die simbool met die referent of toegekende betekenis moet kan verbind. Dit word gedoen op die basis van bestaande konvensie. "Images suggesting further meanings and associations in ways that go beyond the fairly simple identifications of metaphor and simile are often called symbols" 12. In die geval van 'n teks sal so 'n referent gewoonlik ekstratekstueel wees, behalwe as dit spesifiek in die teks self geïdentifiseer word. Sodra daar buite die die sfeer van konsensus ${ }^{13}$ beweeg word, sal die simbool nie meer as simbool kommunikeer nie; byvoorbeeld, 'n oningewyde persoon sal nie die simbole van 'n vreemde kultus verstaan nie. Hulle sal aan daardie persoon verduidelik moet word.

Om dus 'n simbool te interpreteer hang van die leser se vermoë af om die teks te kan dekodeer ${ }^{14}$. Konvensies word gewoonlik nie eksplisiet in die teks gestel nie, maar word as gemeenskaplike kennis tussen skrywer en leser gesien, met ander woorde, as konvensie. Dit maak die interpretasie van veral antieke tekste moeilik, aangesien die hedendaagse eksegeet meermale afhanklik is van toevallige informasie ten einde vas te stel of die outeur en sy lesers 'n spesifieke term of frase as simbool sien. Byvoorbeeld, in die woorde self is daar geen aanduiding dat skape en herder na die God van Israel of Israel self moet verwys nie. Sodra so 'n verband gekonvensionaliseer word, kan gesê word dat herder en skape simbole vir God en sy mense word. Dit is dus glad nie so maklik om vas te stel of 'n sogenaamde simbool werklik 'n simbool is nie. In baie gevalle kom dit neer op interpretasie van wat die oorspronklike lesers presies sou gehoor het. Die eksegeet is dus afhanklik van duidelike aanduidings uit die teks self15.

'n Spesifieke term mag ook "gekonvensionaliseer" word as simbool in 'n spesifieke boek, om sodoende ' $n$ interne simbool in die boek self te word. Byvoorbeeld, "duisternis" en "lig" mag konstant verbind word aan die geestelike dimensies in die teks en so gekonvensionaliseer word in die betrokke geskrif16. Die implisiete leser sal dus terme soos "nag" met die interne simboliese wêreld van "duisternis" verbind op grond van die konvensie wat deur daardie teks self tot stand gebring is. Dit word egter nie 'n simbool wat in alle ander tekste ook so geld nie. Warren \& Wellek noem dit "private symbolism": "Private symbolism' implies a system, and a careful student can construe 'private symbolism' as a cryptographer can decode an alien message" 17 .

Simbole is nie noodwendig stagnant nie, maar kan ook verander. Omdat die bestaan van simbole op konvensie gebaseer is, mag die betekenis van simbole verander soos konvensies verander. Dit maak dit vir Johannes moontlik om van gevestigde simbole gebruik te maak en dit vir sy eie behoeftes aan te pas ${ }^{18}$. 
Dodd19, (en voor hom Kennedy ${ }^{20}$ ), het geargumenteer dat $\sigma \eta \mu \varepsilon \hat{\imath} \alpha$ in die Johannesevangelie eintlik simbole is, aangesien die dade wat uitgevoer word, betekenisvol is en "correspond with something divinely ordained to happen in the real world..."21. $\mathrm{Ng}^{22}$ wys daarop dat die erkenning van die simboliese aard van hierdie vertellings feitlik eenparig is ${ }^{23}$. Die $\sigma \eta \mu \varepsilon \hat{i} \alpha$ as aksies korrespondeer gewoonlik met die gepaardgaande gesprekke en funksioneer so as openbaring. Die $\sigma \eta \mu \varepsilon i \hat{\alpha}$ as tekens kan as simbole beskryf word, veral omdat hulle aan gesprekke verbind word. Op hierdie wyse word simbole in die Evangelie self geskep. Hoewel die $\sigma \eta \mu \varepsilon \hat{\imath} \alpha$ as simbole gesien kan word, sal dit nie verder aandag ontvang in hierdie artikel nie.

Nie alle simbole in die Evangelie gaan hier bespreek word nie, veral nie sekere van die karakteristieke wat verband hou met Jesus, die Jode, sekere feeste, ensovoorts, nie. Daar sal eksemplaries en illustratief te werk gegaan word.

Simbole waarna daar in hierdie artikel verwys word, moet nie verwar word met figuurlike taal in die algemeen of met metafore in besonder nie. Simbole word spesifiek gesien as figuurlike taal wat betekenis vind op die basis van konvensie ${ }^{24}$. Metafore is per definisie vars en onkonvensioneel. 'n Metafoor mag egter 'n simbool word indien die oorspronklike metafoor stabiliseer en fossileer ${ }^{25}$ op die basis van semantiese konvensie.

\section{Simbole in die Evangelie}

Uitdrukkings soos Jesus is die goeie herder of Jesus is die wynstok sluit aan by bekende temas uit die antieke wêreld. Johannes kon goedskiks by bekende uitdrukkings of teksgedeeltes aangesluit het en dit inter-tekstueel in sy teks opgeneem het. Aangesien dit uitdrukkings of tekste is wat binne die konvensie van sy lesers lewe, funksioneer dit as simbole. Vanuit 'n inter-tekstuele perspektief word 'n bekende beeld gebruik, wat dan heraangewend word deur Johannes en so 'n bydrae maak tot die semantiek van Johannes se figuurlike taalgebruik.

Johannes 10 sal meer breedvoerig bespreek word ten einde as voorbeeld te dien, waarna daar kortliks na 'n paar van die ander simbole in die Evangelie verwys sal word. Daar gaan eers vasgestel word of die gedagte van skaapboerdery prominent funksioneer in tekste wat Johannes moontlik kon gebruik het. Uiteraard bied die Ou Testament die basiese vertrekpunt. Verder gaan daar gekyk word na die moontlike verwerking van hierdie gedagtes in die Evangelie. 
Simboliek en die verwysing na skaapboerdery in Johannes 10

Assosiasies van God as herder en Israel as sy skape is 'n algemene tema in die Joodse geskrifte ${ }^{26}$. In Johannes 10 het ons nie 'n presiese weergawe van wat in die Joodse geskrifte gevind word nie, maar die tematiese verwantskap kan nie ontken word nie ${ }^{27}$. Dit wil voorkom of Johannes die Joodse simbool van God as herder neem en dit op Jesus van toepassing maak ${ }^{28}$. Die simbool van Israel as die skape word geherinterpreteer om na diegene te verwys wat in Jesus glo ${ }^{29}$. Hoewel dit nie op sintakties-tekstuele vlak bewys kan word nie, blyk dit tog dat die simboliese waarde van die skaapboerdery in die Joodse geskrifte invloed op Johannes se keuse uitgeoefen het om skaapboerdery as beeld te gebruik. Hy herinterpreteer dit dan en pas dit toe op Jesus en sy volgelinge.

Daar moet dus allereers vasgestel word wat die situasie in die geskrifte van die Ou Testament was. Herders en skape speel 'n belangrike rol in die Ou Testament ${ }^{30}$, ook op figuurlike vlak.

(i) Die leiers van die volk (soos die koning of leiers op godsdienstige gebied) is dikwels beskryf as die herders van die kudde ${ }^{31}$. Op hierdie wyse is hulle verantwoordelikhede sowel as hulle verhouding met hulle onderdane beskryf. Die grafiese beskrywing in byvoorbeeld Numeri 27:16-17 illustreer die punt: "Dan moet $\mathrm{U}$, Here, iemand oor die volk aanstel wat vir hulle 'n leier en aanvoerder kan wees sodat die volk van die Here nie soos skape sonder wagter sal wees nie", of soos 2 Samuel 5:2 dit oor die koningskap van Dawid stel: "Jy moet vir my volk Israel 'n herder wees; ja, jy moet heerser oor Israel wees" ${ }^{32}$. Misbruik van hierdie posisie was in 'n baie negatiewe lig gesien, soos blyk uit die beskrywing in Esegiël 34:110. Die onbesonne gedrag van die leiers van Israel word op figuurlike vlak vergelyk met herders wat hulle skape sleg en brutaal hanteer. 'n Ander algemene uitdrukking is dat mense sonder 'n leier soos skape sonder 'n herder is ${ }^{33}$. Sagaria 13:7-9 gee byvoorbeeld 'n beskrywing van hoe die skape (mense) uitmekaar gejaag word as die herder (die leier) neergevel word ${ }^{34}$.

Daar word meer dikwels klem gelê op die positiewe kwaliteite van die herders, naamlik om die skape te lei en hulle te versorg. Die herder begeer gewoonlik net die beste vir sy skape "dit korrespondeer natuurlik met die funksie van die leier" 35 . Daarom is dit as goeie leerskool vir 'n koning gesien om skape op te pas. Positiewe kwaliteite word so ontwikkel, soos Philo byvoorbeeld argumenteer ${ }^{36}$.

Aangesien God die leier van sy mense is, word Hy dikwels as herder beskryf ${ }^{37}$. Die beste voorbeeld hiervan is waarskynlik Psalm 2338, waar die versorging en beskerming wat die Here aan sy mense gee in terme van 
herderskap beskryf word, terwyl ons ook 'n pragtige beskrywing van God as herder van sy mense in Jesaja 40:11 kry ${ }^{39}$.

Hoewel God in die Ou Testament as herder beskryf word, kan Hy ook herders aanstel ${ }^{40}$. Dit sluit aan by die wyse waarop dorpsmense na hulle skape laat kyk het. Hulle het herders aangestel om oor hulle skape wag te hou. Volgens Jeremia 23:1-4, Esegiël 34:11-12 en Sagaria 10:3 kry ons ' $n$ beskrywing van hoe die aangestelde herders misluk en God self, as eienaar, sy kudde verder versorg. Hy straf dan die ongehoorsame herders $^{41}$. Die idee dat God herders vir sy skape aanstel, blyk meer prominent in die Ou Testament te wees as dat God self die herder is. Die kudde bly God se kudde, maar hulle word deur aangestelde herders versorg.

Johannes 10 en die Petrus-gesprek in Johannes 21 moet teen hierdie agtergrond gelees word. Die huurling is duidelik 'n aangestelde aan wie die skape nie behoort nie. In hoofstuk 21 stel die goeie herder Petrus as versorger van sy skape aan, want die goeie herder gaan weg. In etlike $\mathrm{Ou}$ Testamentiese gedeeltes word hierdie gedagte meer noukeurig uitgewerk.

In Miga 5:1-5 word 'n sterk heerser uit die stam van Juda beloof. Dit word in terme van herderskap gedoen, soos vers 3 (aangehaal uit die

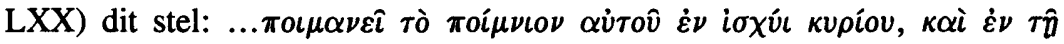

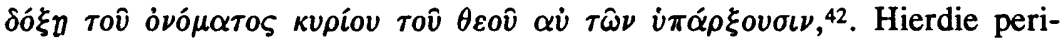
koop word in Matteus 2:6 opgeneem ${ }^{43}$ en Christologies toegepas. Dit beteken dat Jesus die herder is en nie God nie. Dit kan onder andere moontlik wees omdat God herders aanstel, soos Miga 5:1-5 aandui. Dit verhinder God egter nie om self die goeie herder te wees soos Psalm 23 sê nie. Dit sou daarom verkeerd wees om te wil beweer dat Jesus God "vervang" as goeie herder in Johannes 10. In Johannes 21:15-19 plaas Jesus weer die verantwoordelikheid vir die skape op Petrus. Jesus word ook in Openbaring 7:17 die herder genoem, terwyl God die herder genoem word as $\mathrm{Hy}$ al die trane van die gelowiges se oë afvee. Die patroon sluit dus aan by die gangbare gebruike in 'n dorpie waar ander persone wel gevra kan word om agter jou skape te kyk.

In Esegiël 34 word 'n uitgebreide beeld van skaapboerdery aangetref ${ }^{44}$. Verskeie verwante temas word daar aangetref, byvoorbeeld dat die leiers herders is, dat hulle nie vir die skape omgee nie, dat God hulle kan ontslaan, dat God na sy skape kan kyk en hulle na groen weivelde kan lei, en so voorts. In Esegiël 34:23-24 (Es 37:24) word daar gesê dat die Here sy dienskneg Dawid as herder oor sy skape sal aanstel en dat God Here sal wees $^{45}$.

Dit is daarom nie buitengewoon dat Jesus die herder van sy skape genoem word nie. Dit is in ooreenstemming met die Ou-Testamentiese uit- 
drukkings wat hierbo bespreek is ${ }^{46}$, veral in die lig daarvan dat Jesus die Messias is. Dit mag ook die rede wees waarom die tema van Jesus as herder nie net in Johannes 10 voorkom nie, maar ook elders in die Nuwe Testament aangetref word, hoewel die voorkomste aldaar nie 'n hoë frekwensie vertoon nie.

In Matteus 26:31 (Mk 14:27 par)47 word die passie van Jesus geïnterpreteer by wyse van 'n aanhaling uit Sagaria 13:7. Die herder gaan getref word en die skape sal verstrooi word (sien Johannes 16:32). Jesus word hier implisiet met die herder geïdentifiseer. 'n Christologiese herinterpretasie van die Sagaria tradisie lê hier waarskynlik voorhande. In Matteus 26:32 plaas Jesus sy dood in die perspektief van sy opstanding uit die dood (sien Johannes 10:17-18)48. 1 Petrus 2:25 beskryf Jesus ook as herder. Die gelowiges was soos skape wat verstrooi was, maar teruggekeer het na hulle herder. Hierdie is ook 'n bekende tema in die Ou Testament. Skape het ' $n$ herder nodig om te oorleef en dit is presies wat Jesus in Johannes vir sy skape is.

Beutler 49 wys dus tereg daarop dat daar geen parallel in die $\mathrm{Ou}$ Testament is vir die gedagte dat 'n herder vir sy skape sterf nie, behalwe miskien Jesaja 53. Die metaforisasie van die deur (10:7-10) is ook nie 'n Ou-Testamentiese tema nie. Johannes het ook wegbeweeg van die idee van God en sy mense na "the actual relation between Christ and those who belong to him" 50 .

Met al die verwysings na skaapboerdery in die Ou Testament is dit moeilik om met presiesheid vas te stel watter gedeeltes 'n rol kon gespeel het in die vorming van die gedagtes in Johannes 10 . Die parallelle tussen Ou-Testamentiese gedeeltes is tog duidelik en die herinterpretasie van Johannes konsekwent met wat bekend en gebruiklik was in daardie tyd, dat tot inter-tekstuele verbande gekonkludeer kan word. In Johannes 10:7-18 word aan die basiese idees van versorging en beskerming van die skape deur die herder, onder andere in kontras met die huurling aandag gegee. Op hierdie vlak is die inter-tekstualiteit met die Ou-Testamentiese tradisies duidelik. God se mense is afhanklik van Hom net soos skape afhanklik is van hulle herder. Daar is egter nie persiese parallelle tussen die OuTestamentiese materiaal en Johannes 10 nie. Dit onderstreep die uniekheid van die Johannestradisie. Daar is iets ouds en iets nuuts in Johannes 10. Hierdie twee lyne vloei saam en moet as sodanig geïnterpreteer word tot die vorming van nuwe betekenisinhoude. Die gebruik van die herder-skape motief kom egter ook by verskillende outeurs, beide in die Ou- en Nuwe Testament voor, wat op 'n bepaalde verspreidheid en dus bekendheid van hierdie motiewe dui. Dit maak die moontlikheid hoogs waarskynlik dat die 
herder-skape motief tog konvensioneel binne hierdie betrokke gemeenskappe as 'n figuurlike aanduiding van die leier-onderdaan motief gebruik kon word.

\section{Enkele verdere voorbeelde van simbole in die Evangelie}

Wat hier volg is nie 'n volledige lys van simbole in die Johannesevangelie nie, maar alleen enkele geselekseerde voorbeelde ten einde die bevindings hierbo op 'n bietjie breër basis te plaas. Die simbole gaan nie volledig bespreek word nie, maar net 'n breë trekke aangedui word.

Daar word feitlik algemeen aanvaar dat die verwysing na die wynstok in Johannes 15 op die Ou-Testamentiese konvensie gebaseer is. Dit sou dan dui op die mense van $\mathrm{God}^{51}$ as 'n wingerdstok, wat dit natuurlik as simbool kwalifiseer. Jesus, as die wingerdstok, en sy dissipels as die takke, vervang dan Israel wat in die Ou Testament tradisioneel as wingerdstok beskryf is. Op hierdie wyse word 'n ou assosiasie met 'n nuwe een vervang. So word gekommunikeer dat Israel in Jesus voortgesit word en nie elders nie. Die tegniek om simbole nuwe betekenis te gee, is 'n effektiewe manier om die assosiatiewe referensie oor te dra van een element (Israel) na 'n ander (die Kerk): "here he (= Jesus) supersedes Israel as the very locus of the people of $\operatorname{God}^{\prime 52}$. Paschal ${ }^{53}$ is daarom korrek met sy opmerking dat "the personification does not destroy the symbolic nature of these images, but develops them in a new way".

Die gebruik van $\lambda o ́$ yos mag ook simboliese trekke hê. Beide korrespondensie met die Griekse kulturele beskouings en die beskouings uit die Ou Testament mag as basis vir hierdie gebruik dien ${ }^{54}$. Veral ooreenstemming met die Wysheidsliteratuur blyk 'n interessante agtergrond vir die

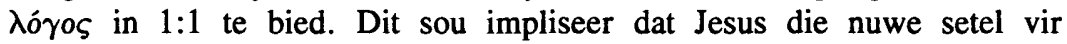
wysheid word. Op dié wyse vind 'n herinterpretasie van die oorspronklike simbool plaas.

Jesus as die "Lam van God" $(1: 29,36)$ is 'n moeilike frase, maar mag ook simbolies van aard wees. Die presiese agtergrond van hierdie uitdrukking is moeilik om vas te stel. Hoe dit ook al sy, Jesus is die Lam en vervul so die simboliese rol van die lam.

Sommige verdere voorbeelde mag Moses en die manna (6:32-33, 49$50)$ of die water wat sal vloei (7:38-39), die lig van die wêreld (8:12 en elders) of die koning van Israel (12:13) wees.

Die enkele voorbeelde wat hierbo genoem is, korrespondeer met dit wat uit Hoofstuk 10 geblyk het. Hierdie wyse van simboliese gebruik kan dus as 'n tipiese gebruik binne die Johannese literatuur beskou word.

Konkluderend dus, moet die leser bewus wees van die konvensies waarbinne sekere motiewe funksioneer ten einde die simboliese waarde 
daarvan effektief te ontsluit, veral in die gevalle waar die simbole herinterpreteer word, soos byvoorbeeld in die Johannes-evangelie.

\section{NOTAS:}

$1 \mathrm{~W}$ Y Ng, Johannine water symbolism and its eschatological significance with special reference to John 4 (Ongepubliseerde PhD: Westminster Theological Seminary), Philadelphia 1997, 6-57, gee 'n weergawe van die verskillende tipes simbole wat onderskei kan word. Sy kom tot die slotsom dat die gebrek aan algemeen aanvaarbare kriteria vir die definiering van simbole 'n ernstige probleem veroorsaak. Sien ook R A Culpepper, Anatomy of the Fourth Gospel. A study in literary design, Philadelphia 1983, 185; C R Koester, Symbolism in the Fourth Gospel. Meaning, Mystery, Community, Minneapolis 1995.

2 In die verband verwys H-J Klauck, Allegorie und Allegorese in synoptischen Gleichnistexten, Münster 1978, 141, na Weinrich and Levin. I Gräbe, Aspekte van poëtiese taalgebruik. Teoretiese verkenning en toepassing, Potchefstroom 1984 , is geneig om dit op hierdie wyse te gebruik.

3 O Schwankl, Licht und Finsternis. Ein metaphorisches Paradigma in den johanneischen Schriften, Freiburg, 1995, 363.

4 J van Luxemburg, $M$ Bal, \& W G Weststeijn, Inleiding in de literatuurwetenschap, Muiderberg, 1988, 242.

5 Verskillende pogings is al gemaak om tussen simbool en metafoor te onderskei. Sien byvoorbeeld J Macquarrie, Gott-Rede. Eine Untersuchung der Sprache und Logik der Theologie, Würzburg, 1974, 174-175; Schwankl $a w, 362$; Koester $a$ $w, 6-7$.

6 P Tillich, "The religious symbol", Journal of liberal religion II, 1940, 13-33 onderskei sekere karakteristieke van simbole. Hy noem onder andere: hulle is figuurlik van aard wat beteken dat hulle nie belangrik is vir wat hulle is nie, maar vir dit waarvoor hulle staan; hulle maak 'n onbevatlike realiteit bevatlik; hulle het ' $n$ sosiaal aanvaarbare in plaas van net ' $n$ ideosinkratiese betekenis; dit verwys na die "unconditioned transcendent".

$7 \quad$ C Baldich, The Concise Oxford Dictionary of Literary terms, Oxford 1990, 218219. Koester $a w, 4$ definieer simbool baie wyd: "A symbol is an image, an action, or a person that is understood to have transcendent significance". Dit maak alles in die Evangelie figuurlik. Koester motiveer ook nie waarom hy simbole beperk tot hulle "transcendent significance" nie, behalwe dat hy beweer dat dit is hoe dit in Johannes funksioneer. Hy beperk ook simbole tot "images that can be perceived by the senses" en word daarvoor gekritiseer deur $\mathrm{Ng} a w, 8-9$; R W Paschal, "Sacramental symbolism and physical imagery in the Gospel of John", Tyndale Bulletin 32 (1981), 151-176; C H Dodd, The interpretation of the Fourth Gospel, Cambridge 1978, 133-143; D A Lee, The symbolic narratives of the Fourth Gospel: The interplay of form and meaning. (JSNT Suppl. 95), Sheffield 1994, 29.

8 Van Luxemburg et al, a w, 242 beklemtoon ook die belang van konvensie. Hulle beskryf 'n simbool as "een teken waarbij datgene waarnaar verwezen wordt op grond van associaties iets meer en iets anders betekent". Baldich, $a w$, 218-219 sluit hierby aan as hy sê: "In the semiotics of C S Peirce, the term 
(symbolism) denotes a kind of sign that has no natural or resembling connection with its referent, only a conventional one: this is the case with words".

9 Schwank1, $a w, 362$.

10 A Warren, \& R Wellek, Theory of literature, London 1955, 193 beweer daar is 'n soort van intrinsieke relasie tussen "teken" en "betekende". Dit hoef nie altyd so te wees nie. Culpepper, $a w, 182$ onderskei ook tussen tekens en simbole. Tekens word meer arbitrêr gebruik ten einde na iets anders as sigself te verwys. Daar hoef nie 'n intrinsieke konneksie tussen teken en dit waarna dit refereer te wees nie. Simbole kan ook tekens wees. Sien ook $\mathrm{Ng}, a w, 10$.

11 E R Goodenough, Jewish symbols in the Greco-Roman Period, Princeton 1988, 50.

12 Baldich, $a w, 106$.

13 Dit mag gebeur as daar na 'n ander groep mense beweeg word wat nie die konvensies deel nie, of wanneer die konvensie nie voortgesit word nie of binne 'n betrokke gemeenskap vergeet word. 'n Simbool funksioneer alleen as dit deur 'n gemeenskap aanvaar word en binne die sfeer van daardie gemeenskap lewendig gehou word.

14 Sien S M Schneiders, "History and symbolism in the Fourth Gospel", in: M de Jonge (ed), L'Evangile de Jean: source, rédaction, théologie (BETL 44), Lovain 1977, 371-372. Verskillende groepe (bv die Grieke, Jode, Helleniste of Romeine) het natuurlik nie almal dieselfde konvensies gedeel rakende simbole nie. In 'n evangelie soos Johannes, het die gehoor wat heelwaarskynlik gemeng kon wees, heel moontlik nie dieselfde konvensies gedeel nie. Tog moet daar onthou word dat hulle lede van dieselfde gemeentegroep was. Sekere konvensies moes hulle dus gedeel het en indien nie, kon hulle mekaar inlig.

15 Van Luxemburg et al, $a w, 242$.

16 Johannes gebruik bestaande simbole soos die wyn (Hoofstuk 2) of die herder (Hoofstuk 10). Hy skep ook simbole in die Evangelie self deur konstant 'n sekere saak met 'n spesifieke referensie te verbind. Op hierdie wyse word metafore of ander uitdrukkings simbole in die Evangelie.

17 Warren \& Wellek, $a w, 194$.

18 Schwankl, $a w, 364-369$, bespreek hierdie saak verder.

19 Dodd, $a w, 141-143$.

20 H A A Kennedy, Philo's contribution to Religion, London 1919, 46.

21 Dodd, $a w, 141$. Sien ook Culpepper, $a w, 185$.

$22 \mathrm{Ng}, a w, 9$.

23 Teen D W Wead, The literary devices in John's Gospel, Basel 1970; Sien ook verder $\mathrm{Ng}, a w, 9-11$.

24 Ek stem dus saam met Schwankl, a $w, 362$ dat “die Differenz sehen wir vor allem darin, dass die Metapher stärker als das Symbol an die Sprache gebunden, das Symbol also stärker aussersprachlich bestimmt ist" en dat "die Metapher in ihrer Bedeutung weniger festgelegt ist als das Symbol; sie ist beweglicher, stärker prozesshaft, das Symbol stabiler, eher statisch".

25 D Geeraerts, Woordbetekenis. Een overzicht van de lexicale semantiek, Leuven 1986, 50-52 wys daarop dat sodra die oorspronklike interaksie tussen "tenor" en "vehicle" in 'n metafoor nie meer langer aktief funksioneer nie, begin fossilering reeds. Sien ook M Hesse, “Die kognitiven Ansprüche der Metapher”, in: 
Van Noppen (Hrsg.), Erinnern, um Neues zu sagen, Frankfurt am Main 1988, 132. Hierdie is egter ' $n$ onstabiele kriterium om mee te werk, aangesien fossilering van individuele lesers en hulle kontekste afhanklik is. Dit bly 'n fliktuerende katagorie.

26 E Beyreuther, "Shepherd" in: C Brown (ed) NIDNT vol 3, 1978, 564, wys daarop dat die term herder algemeen deur Israel en hulle bure gebruik is. Die term is gebruik vir beide hulle gode en heersers. Dit kan byvoorbeeld in die Sumeriese koninglyste, asook in die Babiloniese hoftaal gesien word. Jahwe word ook herder genoem, veral in die Psalms. Hierdie wyse van figuurlike taalgebruik was dus algemeen in die antieke wêreld. Plato (Republic 4.440d) het reeds die heersers van die stadstate met herders vergelyk. Die tekste van die Ou Testament moet egter as primêre bronne vir inter-tekstualiteit in die Johannesevangelie gesien word.

27 J A T Robinson, "The destination and purpose of St John's Gospel", NTS 6, 1959/60, 123 beweer: “...the distinctive images which Jesus is made to use of himself in this Gospel - the Manna (vi. 32-5), the Light (viii. 1), the Shepherd (x. 11-16), the Vine (xv, 1-6) - all by their associations in the Old Testament and later Judaism represented him in his person as the true Israel of God".

28 C K Barrett, The Gospel according to St John (2nd edition), London 1978, 367, voer Hoofstuk 10 terug na al die gelykenisse in die Ou Testament oor herders asook sulke verwysings in die res van die Nuwe Testament.

29 Paschal, $a w, 152-153$.

30 J Gnilka, Johannesevangelium, Würzburg, 1983, 81, beklemtoon dit ook en verwys na Jesaja 63:11; Esegiëla 34:1-16; Psalm 77:21. Hy wys tog ook daarop dat die temas uit die Ou Testament nie die gebruikswyses in Johannes 10 volledig dek nie.

31 Sien 2 Samuel 24:17; Psalm 78:71-72; Jeremia $3: 15 ; 6: 3 ; 22: 22 ; 23: 2$, 4; Esegiël 34; Acts 20:28; 1 Petrus 5:2; Openbaring 2:27; Filo, On the embassy of Gaius, V (20); VII (43). In die Griekse tradisie gaan hierdie idee terug na Homerus wat deur Aristoteles, Nicomachean Ethics, 8 (11) aangehaal word asook deur Filo, Every good man is free, III (31); On Joseph I (2-4). Sien ook Plato, Gorgias 155.177. Die frekwensie van hierdie idee blyk laer te wees onder die Griekse fikosowe, behalwe vir Plato wat die idee gebruik in Republic 71.646; 276.646 and Statesman 22.124; 29.124; 42.124. Vergelyk J D Turner, "The history of religions background of John 10" in: J Beutler, \& R T Fortna (eds), The shepherd discourse in John 10 and its context, Cambridge 1991, 3538; Barrett, $a w, 373-374$ wys daarop dat hierdie nie net 'n tipiese Joodse idioom is nie, maar dat dit algemeen in gebruik was. Koester, $a w, 14$ wys daarop dat leierskap en herderskap verbind word, beide in die Joodse geskrifte asook in die Griekse klassieke literatuur, byvoorbeeld in die Iliad 2.243ff and Plato in Rep. Discourses 3.22.35.

321 Kronieke 11:2 par. Hierdie tema word opgeneem in Matteus 9:36 (Mk 6:34 par) en reflekteer op die geestelike situasie van die mense in die stede wat Jesus besoek het. ' $n$ Verdere interessante punt is dat die tema van oes, wat so prominent in Johannes 4 voorkom, met die skaap en herdermotief in Matteus 9:36-37 verbind word. 
33 Sien 1 Konings 2:17; 2 Kronieke 18:16; Judit 11:19; Sagaria 10:2; Matteus 9:36; Markus 6:34; Filo, On the posterity of Cain and his exile, XIX (66-68); On Humanity $X$ (58).

34 Johannes 16:32 verwys waarskynlik hierna.

35 Plato, Republic 71.646 beklemtoon dit.

36 On the life of Moses, XI (60-62).

37 Hierdie idee is prominent in Joodsverwante godsdienste, maar word ook byvoorbeeld aangetref in Plato, Statesman 36.124; 42-45.124. Plato argumenteer dat gode oor mense heers soos konings oor hulle onderdane heers. Hulle status is egter hoër as die van konings.

38 Filo, On Husbandry XII (49-53), noem God ook herder in 'n konteks waar die konings en leiers 'n rol speel. Hy haal ook Psalm 23 aan wat iets sê oor die Wirkungsgeschichte van Psalm 23.

39 Sien Psalm 28:9; 80:1; Jesus Sirag 18:13. In Psalm 47:15 (LXX) word die sorg en leierskap van God in terme van herderskap geformuleer (Sien ook Hos 13:5). In Esegiël 34:11-12 neem God die rol van herderskap oor, maar stel later 'n ander herder aan (Es 34:23-24).

$40 \quad$ Byvoorbeeld Psalm 78:71-72; Jeremia 3:15; 23:3-4; Esegiël 34; 37:24; Sagaria 11:4-17.

41 Sien ook Esegiël 34:7-10; Sagaria 11:17.

42 "hy sal sy skape oppas deur die krag van die Here; deur die belangrikheid van die Here hulle God".

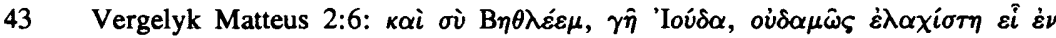

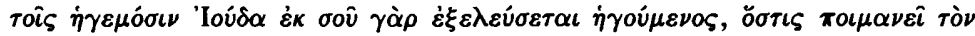

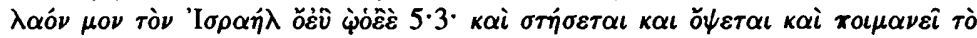

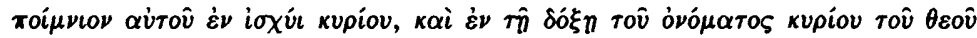

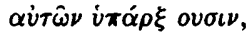

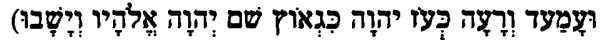

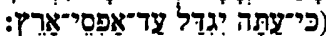

44 Sien ook Sagaria 11:4-17.

45 Hierdie kan as Messiaanse uitdrukking gesien word, aangesien Dawid, koning van Israel, reeds vir sowat vierhonderd jaar dood was en daar geen ander koning Dawid daama bekend is nie. Die Messias word so genoem omdat Hy van Dawid afstam en omdat die beloftes wat aan Dawid gemaak is, in Hom vervul is (Jes 55:3-4; Jer 30:9; Op 22:16).

46 Sien ook J Beutler, "Der alttestamentlich-jüdische Hintergrund der Hirtenrede in Johannes 10", in: J Beutler, \& R T Fortna (eds), The shepherd discourse in John 10 and its context, Cambridge, 1991, 29-30.

47 Turner, $a w, 43-45$ is skepties oor direkte verbande tussen die sinoptiese gebruik van die herdermotief en die wyse waarop Johannes dit gebruik: “Clearly, as Bultmann recognized, the conceptions of this passage are either original with the Evangelist, or derived from other quarters that the known parables of Jesus" (45).

48 J A T Robinson, "The parable of John 10,1-5", ZNW 46(1955), 235 sien affiniteite tussen hierdie beeld en die verwysings na skape in die Sinoptiese 
evangelies, byvoorbeeld in Matteus 15:24; 18:12-14; Markus 14:27f.; Lukas 12:32; 15:4-7. Sien ook P Riga, "Signs of glory. The use of 'semeion' in St John's Gospel”, Interpretation 17(1963), 407.

49 Beutler, $a w, 29-30$.

50 N A Dahl, "The Johannine Church and History", in: W Klassen (ed), Current issues in New Testament Interpretation, Essays in honour of Otto A Piper, New York 1962, 125.

51 D A Carson, The Gospel according to John, Leicester 1991, 511, wys daarop dat die verwysings na wingerde in die Sinoptiese evangelies almal na Israel verwys. Daar word gewoonlik na die gebrek aan vrugte verwys. Dit is ook 'n algemene beeld in ander religiee. In die Ou Testament word dit byvoorbeeld aangetref in Psalm 80:9-16; Jesaja 5:1-7; 27:2-9; Jeremia 2:21; 12:10-11; Esegiël 15:1-8; 17:1-21; 19:10-14; Hosea 10:1-2.

52 Carson, $a w, 513$.

53 Paschal, $a w, 152$.

54 Carson, $a w, 114-116$. 